\title{
Evolution of volatile compounds and physical, chemical and sensory characteristics of Toscano PDO ham from fresh to dry-cured product
}

\author{
Francesco Sirtori ${ }^{1} \cdot$ Corrado Dimauro $^{2} \cdot$ Riccardo Bozzi $^{1} \cdot$ Chiara Aquilani $^{1}$ (i) $\cdot$ Oreste Franci ${ }^{1} \cdot$ Luca Calamai $^{1}$. \\ Antonio Pezzati ${ }^{1} \cdot$ Carolina Pugliese $^{1}$
}

Received: 30 July 2019 / Revised: 7 November 2019 / Accepted: 16 November 2019 / Published online: 28 November 2019

(c) The Author(s) 2019

\begin{abstract}
Physical and chemical changes in Toscano ham lean were evaluated according to three different seasoning time (14, 16 and 18 months). Moreover, on Semimembranosus muscle, the volatile profile at 0, 1, 3, 6, 12, 14, 16 and 18 months of seasoning was determined by SPME-GC-MS. Eventually, a quantitative-descriptive sensory evaluation was performed. Longer seasoning times led to a decrease of Chroma in Biceps femoris, and also protein and proteolysis index decreased as the seasoning time increased. A total of 97 volatile compounds (VOCs) belonging to seven chemical families (29 aldehydes, 16 esters, 14 alcohols, 13 hydrocarbons, 12 ketones, 10 acids, 2 furans and 1 nitrogenous compound) were identified. Sensory evaluation outlined the major differences between 18th months ham and the other two classes, with the former being harder and with a slight presence of off flavor and off odor. The VOCs evolution during curing was studied and a multivariate approach was performed to test the feasibility of using the VOCs profile to predict the curing stage of Toscano ham. The discriminant analysis successfully managed to separate the samples of 0-6 months from the ones of 12-18 months using 26 of the identified VOCs. Among them, pentane 2,3-dimethyl, acetophenone and 9-decenoic acid were strong discriminants for 0-6 months hams, while dodecanoic, benzeneacetaldehyde, 3-octen-2-one and pentanoic acid ethylester were linked to 12-18 months hams. Within the high maturing classes $(12,14,16,18$ months of seasoning), the 17 discriminating compounds identified successfully allocated only 12 and 18 months samples. The main VOCs associated with the " 12 months" class were nonanal, 1,5-diphenyl-3-methylthio-1,2,4-triazole and 6-methoxy 2-hexanone. The "18 months" seasoning class, instead, was identified by 1,5-diphenyl-3-methylthio-1,2,4-triazole, phenol and 1,2-butoxy ethanol.
\end{abstract}

Keywords Aromatic profile $\cdot$ Seasoned ham $\cdot$ Multivariate analysis $\cdot$ Discriminant analysis $\cdot$ Curing time $\cdot$ GC-MS

\section{Introduction}

In the last decades, the analysis of volatile compounds (VOCs) was widely performed to characterize the dry-cured products and, in particular, the dry-cured ham [1-4]. Indeed, in Europe, several PDO dry-cured hams have been established, i.e., Parma, San Daniele, Toscano and Iberian represent pivotal productions in their respective countries, due to their economic value and their extraordinary consumer

Chiara Aquilani

chiara.aquilani@unifi.it

1 Dipartimento di Scienze e Tecnologie Agrarie, Alimentari, Ambientali e Forestali, Università di Firenze, Scuola di Agraria, Via delle Cascine 5, 50144 Florence, Italy

2 Dipartimento di Agraria, Università degli Studi di Sassari, Viale Italia 39, 07100 Sassari, Italy acceptance. Many factors were identified as responsible for influencing the dry-cured ham sensory profile, especially in relation to VOCs [5]. Among them, a pivotal role is certainly carried out by the length of curing process [6], during which a series of enzymatic and non-enzymatic reactions take place, leading to the development of a large number of VOCs and, consequently, to the characteristic sensorial attributes of ham. Although the influence of different curing times has been widely investigated, few studies are available on the VOCs trend during the different stages, from green to dry-cured ham [7-9].

Furthermore, since the dry-cured ham is a very complex matrix, where the contribution to flavor development can occur both from fat and lean tissue [10], a differentiation between lean and fat VOCs' profile seemed to be an interesting topic. Moreover, it is well known that the main family of volatile compounds, such as aldehydes, originated both 
from lipid oxidation and from protein degradation through Maillard reaction [9].

The modification in VOCs composition, linked to the change of some discriminant factors (curing time, salt reduction, etc.), is generally due to a quantitative difference among compounds rather than the presence of a "marker compound"; the entire pool of VOCs can be used as an element of characterization (a kind of aromatic fingerprint) generated by processing data through appropriate statistical tests. Several authors $[9,11,12]$ have already used a multivariate approach, such as the principal component analysis (PCA), to explore VOCs data. In the present research, however, alternative statistical approaches, such as the canonical discriminant analysis (CDA) and the discriminant analysis (DA), were preferred to PCA to analyze data. CDA is a multivariate statistical technique specifically conceived to discriminate groups and to highlight variables that better separate those groups. Furthermore, the DA is particularly useful to classify objects into groups.

The aim of this work was to study the physical, chemical and sensory characteristics, as well as the aromatic pattern of Semimembranosus muscle in Toscano dry-cured ham starting from the green ham until 18 months of ripening. Moreover, the CDA and the DA were tested to assess the feasibility of using them to classify the hams in the different curing ages.

\section{Materials and methods}

\section{Samples}

A total of 30 hams were used for the present study. Samples were divided into three groups of ten hams each, which were seasoned for 14, 16 and 18 months, respectively. Green hams weighed $15.60 \pm 1.06 \mathrm{~kg}$ and they were manufactured and seasoned in an industrial plant until they reached the final weight of $10.73 \pm 0.88 \mathrm{~kg}$, according to the 'Toscano' PDO Consortium manufacturing protocol. The protocol foresees the following phases: salting (15-18 days), pre-resting
(15 days), resting (60-70 days), drying (10 days), ripening ( $\sim 240$ days) and seasoning (after 12 months). At the established time (14, 16 or 18 months), hams were dissected to perform the physical, chemical and sensory analysis. Moreover, the hams belonging to the 18-month group were sampled along the whole curing period (at $0,3,6,12,14,16$ and 18 months) as described in "Volatile compound analysis".

\section{Physical and chemical parameters}

Curing loss was expressed in percentage and measured as difference between initial weight (time 0 ) and final weight (14, 16 or 18 months depending on seasoning cluster). At the end of each seasoning time (14, 16 or 18 months), ten hams were dissected and on Semimembranosus muscles color $\left(\mathrm{L}^{*}, \mathrm{a}^{*}\right.$ and $\left.\mathrm{b}^{*}\right)$ parameters were determined by a Minolta Chromameter CR200 with illuminant C (Tokyo, Japan), immediately after slicing. Starting from these data chroma and hue angle were calculated. Moisture was determined by lyophilizing to constant weight $40 \mathrm{~g}$ of sample, according to AOAC methods [13]. Total protein, fat and ash contents were determined following the AOAC [13] methods. The salt content was assessed by Volhard method (ISO 18411). Fatty acids were determined using a Varian GC-430 apparatus equipped with a flame ionization detector (FID) (Palo Alto, CA, USA) as reported by Sirtori et al., [14]. The individual methyl esters were identified by their retention time using an analytical standard (F.A.M.E. Mix, C8-C22 Supelco 18,9201AMP). Response factors based on the internal standard (C19:0) were used for quantification and results were expressed as $\mathrm{g} / 100 \mathrm{~g}$ of sample.

\section{Volatile compound analysis}

Each ham of the 18 months group was sampled immediately after trimming (0) and after 1, 3, 6, 12, 14, 16 and 18 months of ripening. These sampling times were chosen according to the temperature and the relative humidity regimes that varied during curing (Table 1). Semimembranosus muscle was sampled using a 5-mm punch corer. Sampling was performed
Table 1 Ripening phases and processing conditions of Toscano ham

\begin{tabular}{lllll}
\hline Phase & Temperature ${ }^{\circ} \mathrm{C}$ & $\begin{array}{l}\text { Relative humid- } \\
\text { ity } \%\end{array}$ & Days per phase & Cumulate days \\
\hline Salting & $1.5-3.5$ & $70-80$ & $15-18$ & \\
Pre-resting & $2-4$ & $50-70$ & 15 & $30-33$ \\
Resting & $2-4$ & $55-75$ & $60-70$ & $90-103$ \\
Pre-drying & $25^{\mathrm{a}}$ & $50-70$ & $(8 \mathrm{~h})$ & $100-113$ \\
Drying & $16-18$ & $50-70$ & 10 & $190-203$ \\
Pre-seasoning & $16-18$ & $55-75$ & 90 & 370 \\
Seasoning & $16-18$ & $60-80$ & 180 & \\
\hline
\end{tabular}

${ }^{\mathrm{a}}$ The inner ham reaches a maximum of $20^{\circ} \mathrm{C}$ 
approximately in the same location. After each sampling, the hole was filled with a mixture of lard, salt and pepper to prevent oxidation reactions and microbial contaminations. For sample preparation, $1 \mathrm{~g}$ of homogenized muscle, ground by liquid nitrogen, was transferred to $10 \mathrm{~mL}$ screw cap headspace vials and, for each sample, $1 \mathrm{~mL}$ of distilled water and approximately $1 \mathrm{~g}$ of $\mathrm{NaCl}$ were added. The vials were supplemented with $40 \mu \mathrm{l}$ of internal standard (ethylacetated8; toluene-d8; ethyl hexanoate-d11; hexanoic acid-d11; 3,4-dimethylphenol). The compound in the internal standard were either isotopologues, i.e., deuterated analogs of compounds present in the samples, or similar compounds but not found in the speciments. The mix added to the samples immediately before the analyses [15].

The volatile compound profile was obtained by the SPME-GC-MS technique. An Agilent 7890 Chromatograph equipped with a 5975A MSD with EI ionization was used for analysis. A three-phase DVB/Carboxen/PDMS 75- $\mu \mathrm{m}$ SPME fiber (Supelco, Bellafonte, PA, USA) was exposed in the headspace of the vials at $60{ }^{\circ} \mathrm{C}$ for $30 \mathrm{~min}$ for volatile compound sampling after a 5 -min equilibration time. A Gerstel MPS2 XL autosampler equipped with a magnetic transportation adapter and a temperature-controlled agitator (250 rpm with on/cycles of $10 \mathrm{~s}$ ) was used for ensuring consistent SPME extraction conditions. Chromatographic conditions were column J\&W Innovax $30 \mathrm{~m}, 0.25 \mathrm{~mm}$, ID $0.5 \mu \mathrm{m}$ DF; injection temperature $250^{\circ} \mathrm{C}$, splitless mode, oven program $40^{\circ}$ for $1 \mathrm{~min}$, then $2{ }^{\circ} \mathrm{C} / \mathrm{min}$ to $60{ }^{\circ} \mathrm{C}, 3{ }^{\circ} \mathrm{C} / \mathrm{min}$ to $150{ }^{\circ} \mathrm{C}, 10^{\circ} \mathrm{C} / \mathrm{min}$ to $200{ }^{\circ} \mathrm{C}$, and $25^{\circ} \mathrm{C} / \mathrm{min}$ to $260{ }^{\circ} \mathrm{C}$ for $6.6 \mathrm{~min}$. Mass spectra were acquired within the $29-350 \mathrm{M} / \mathrm{Z}$ interval with an Agilent 5975C MSD spectrometer at a scan speed to obtain three scans/s. The identification of volatile compounds was done on the basis of both matching of the peak spectra with library spectral database and matching of the calculated Kovat index (KIS) with the KIS retrieved from literature. Data are expressed as normalized area ratios with the appropriate internal standard (IS).

\section{Sensory analysis}

Once they reached the desired seasoning time $(14,16$ or 18 months), hams were boned and cut at knee level into two sections. Slicing was carried out perpendicularly to the bone to obtain $0.8 \mathrm{~mm}$-thick slices comprehensive of Biceps femoris, Semimembranosus and Semitendinosus muscles. Sensory analysis was performed by a trained panel of 12 judges using a descriptive analysis method: 15 traits regarding sensory characteristics of ham, grouped in appearance, texture, taste and aroma, were studied. A 10-cm unstructured scale was used, whose extremes were "very low" and "very high". Hams were sliced immediately before each session and tasting was performed on two samples of each ham. All sessions were done at $20-24{ }^{\circ} \mathrm{C}$ in a panel room equipped with fluorescent lighting, and panelists were invited to drink a glass of water and eat a cracker between one sample and the following one.

\section{Statistical analysis}

Data were analyzed using SAS Software [16] according to the following linear model:

$y_{\mathrm{ij}}=\mu+\mathrm{RT}_{\mathrm{i}}+H_{\mathrm{j}}+\varepsilon_{\mathrm{ij}}$,

where $y$ is the volatile compound; $\mu$ the overall mean; RT the fixed effect of curing time ( 8 levels); $\mathrm{H}$ the random effect of ham (with repeated measures in time); and $\varepsilon$ the random residual error. Tukey's test with a $p$ value threshold lower than 0.05 was used to compare means. For sensory analysis, the effect of panelist was also added to the model.

Three multivariate statistical techniques were used to analyze the VOCs behavior: the canonical discriminant analysis (CDA), the stepwise discriminant analysis (SDA) and the discriminant analysis (DA). All statistical analyses were developed by using the SAS software (SAS Institute, Inc.).

The CDA defines a set of new variables, called canonical functions (CAN), which are linear combinations of the original characters. In general, if k-groups are involved in the CDA, $\mathrm{k}-1 \mathrm{CANs}$ are extracted. The structure of a CAN is:

$\mathrm{CAN}=c_{1} X_{1}+c_{2} X_{2}+\cdots+c_{n} X_{n}$,

where $c_{i}$ are the canonical coefficients $(\mathrm{CCs})$ and $X_{i}$ are the scores of original variables. CCs indicate the partial contribution of each variable in composing the CAN. The greater the $\mathrm{CC}$, the more the related variable contributes in composing the CAN. The distance between groups was calculated by using the Mahalanobis distance (MD), a metric particularly useful in a multivariate space when some variables are correlated. The formula is:

$\operatorname{MD}(x)=\sqrt{ }(x-\mu)^{T} S^{-1}(x-\mu)$,

where $x=\left(x_{1}, x_{2}, \ldots, x_{n}\right)^{T}$ is an observation from a set of observations with mean $\mu=\left(\mu^{1}, \mu^{2}, \ldots ., \mu^{n}\right)^{T}$ and covariance matrix $S$. The effective separation between groups was tested with the Hotelling's $T$-square test [17]. However, this test can be developed only if the pooled (co)variance matrix of data is not singular. In our research, the number of hams (rows in the matrix of data) is lower than the number of volatile compounds (columns). In this condition, any multivariate technique becomes meaningless because the (co) variance matrix does not have a full rank [18]. Therefore, a reduction of the space variables is required. For this reason, before CDA, the SDA was applied to the data. SDA is a multivariate statistical technique specifically conceived to select 
the subset of variables that better discriminate groups. In the present research, the SDA selects compounds exploited to develop both the CDA and the DA. The latter technique was used to classify ham samples into seasoning groups.

The above-mentioned discriminant procedures were successively applied to volatile compounds data according to the following two scenarios. In the first scenario, VOCs data were arranged in two major curing classes: the low maturing class (LMC) with samples belonging to $0,1,3$ and 6 months; the high maturing class (HMC) with samples belonging to $12,14,16$ and 18 months of seasoning. In the second scenario, only samples belonging to HMC were considered.

The discriminant procedures were applied to detect the most discriminant compounds able to correctly separate groups involved in the two scenarios. To validate the results, considering the reduced number of involved hams, the leaveone-out cross-validation technique was adopted. In practice, in each scenario, SDA, CDA and DA were applied ten times (10 hams being involved in the study) by using, at each run, one ham as a validation sample. At the end, ten datasets of variables were obtained. Since compounds selected at each round could be different, the ten groups of variables were joined. The resulting compounds were used to develop the final run of CDA and DA.

\section{Results and discussion}

\section{Physical and chemical analysis}

Along the curing process, hams lose weight due to an increasing loss of water from 0 to 18 months of curing $(6,16,23,27 \%$ at $1,3,6,12$ month respectively, data not shown), with a plateau between 14 and 16 months (Table 2). Consequently, moisture showed a light tendency to decrease from 14- to 18-month hams, in line with what is generally observed in dry-cured ham [19-21]. Some modifications in protein content were also observed between seasoning classes, especially between 14- and 16-month hams and the 18-month group. This is probably due to an increased proteolysis activity along curing, as observed by Benedini et al. [22].

Instrumental color did not show any difference in the Semimembranosus muscles among the seasoning classes. Contrariwise, changes in color traits were observed in Celta ham, where Biceps femoris was less red and bright in the final seasoning phase [19], and in Teruel PDO drycured ham [23], and a progressive decrease of CIELAB parameters in lean ham was observed also by Giovannelli et al. [21] for three Italian PDO dry-cured hams. In the latter study, as the curing process advances, Toscano ham was the one that showed the greater decrease in lightness during the last seasoning phases.

The evolution of fatty acid profile (Table 3 ) from green to cured ham outlined some significant differences for C12:0, C14:0, C16:0, C16:1-n7, C17:0, C17:1, C18:1-n9 and $\mathrm{C} 18: 1-\mathrm{n} 7$, whose amounts were greater in green ham than in cured products, especially for hams seasoned for 14 and 16 months. Total saturated (SFA) and monounsaturated (MFA) fatty acids showed the same decreasing pattern from 0 to 14 or 16 months of curing and, even if polyunsaturated fatty acids (PUFA) $\mathrm{n} 3$ and PUFA $n 6$ were similar, $\mathrm{n} 6 / \mathrm{n} 3$ ratio was lower in green hams with respect to 14- and 16-month hams. Eventually, total lipids decreased from 0 to 14 and 16 months. Comparable findings were observed for $\mathrm{C} 16: 0$ between green and seasoned Iberian ham [24], for C18:1 and MUFA contents between 12- and 16-month Kraški pršut Semimembranosus muscle [25] and between green and cured hairless Mexican pig ham [26]. Moreover, the decrease in total fatty acids was anticipated due to lipid oxidation processes taking place during the curing and outlined by VOCs profile evolution. The fatty acid evolution along the curing, including the results related to the 18-month cured hams was partially unexpected and it would need further researches, though similar results have already been reported for Teruel, Iberian and Corsican dry-cured hams [27-29].
Table 2 Physical parameters and chemical composition of Toscano ham Semimembranosus muscle

\begin{tabular}{llllcc}
\hline & 14 & 16 & 18 & RMSE & $P$ \\
\hline Curing loss (\%) & $28.27 \mathrm{~b}$ & $29.43 \mathrm{~b}$ & $30.94 \mathrm{a}$ & 1.51 & $<0.0001$ \\
Moisture (\%) & 28.04 & 27.18 & 27.36 & 1.11 & 0.058 \\
Protein (\% on dry matter) & $76.71 \mathrm{a}$ & $77.14 \mathrm{a}$ & $74.92 \mathrm{~b}$ & 1.71 & 0.022 \\
Fat (\% on dry matter) & 4.10 & 3.79 & 4.05 & 1.05 & 0.779 \\
Ash (\% on dry matter) & 12.84 & 12.43 & 11.84 & 1.05 & 0.137 \\
Sodium nitrite (\% on dry matter) & 5.41 & 5.52 & 5.33 & 0.56 & 0.756 \\
Proteolysis index & $0.29 \mathrm{a}$ & $0.28 \mathrm{a}$ & $0.26 \mathrm{~b}$ & 4.00 & $<0.0001$ \\
Chroma & 14.20 & 13.74 & 14.14 & 8.11 & 0.636 \\
Hue & 0.37 & 0.34 & 0.40 & 12.51 & 0.059 \\
\hline
\end{tabular}

*Different letters $(\mathrm{a}, \mathrm{b})$ among seasoning classes indicate significant differences $(P<0.05)$ 
Table 3 Fatty acid profile $(\mathrm{g} / 100 \mathrm{~g})$ of Toscano ham according to seasoning time

\begin{tabular}{|c|c|c|c|c|c|c|}
\hline & 0 & 14 & 16 & 18 & RMSE & $P$ \\
\hline Total lipids & $6.44 \mathrm{a}$ & $5.27 \mathrm{~b}$ & $5.01 \mathrm{~b}$ & $6.21 \mathrm{ab}$ & 1.53 & 0.040 \\
\hline C12:0 & $0.04 \mathrm{a}$ & $0.02 \mathrm{~b}$ & $0.03 \mathrm{ab}$ & $0.04 \mathrm{a}$ & 0.01 & 0.028 \\
\hline $\mathrm{C} 14: 0$ & $0.10 \mathrm{a}$ & $0.07 \mathrm{~b}$ & $0.07 \mathrm{~b}$ & $0.10 \mathrm{ab}$ & 0.03 & 0.028 \\
\hline C14:1-n5 & 0.00 & 0.00 & 0.00 & 0.01 & 0.00 & 0.271 \\
\hline C15:0 & 0.00 & 0.00 & 0.00 & 0.01 & 0.00 & 0.191 \\
\hline C16:0 & $1.38 \mathrm{a}$ & $1.14 \mathrm{ab}$ & $1.07 \mathrm{~b}$ & $1.35 \mathrm{ab}$ & 0.35 & 0.051 \\
\hline C16:1-n9 & 0.04 & 0.03 & 0.03 & 0.04 & 0.01 & 0.119 \\
\hline C16:1-n7 & $0.29 \mathrm{a}$ & $0.21 b c$ & $0.19 \mathrm{c}$ & $0.26 \mathrm{ab}$ & 0.08 & 0.003 \\
\hline C17:0 & $0.01 \mathrm{~b}$ & $0.01 \mathrm{ab}$ & $0.01 \mathrm{ab}$ & $0.02 \mathrm{~b}$ & 0.01 & 0.038 \\
\hline C17:1 & $0.02 \mathrm{a}$ & $0.01 \mathrm{~b}$ & $0.01 \mathrm{ab}$ & $0.02 \mathrm{ab}$ & 0.01 & 0.050 \\
\hline C18:0 & 0.61 & 0.52 & 0.50 & 0.57 & 0.15 & 0.133 \\
\hline C18:1-n9 & $2.63 \mathrm{a}$ & $2.00 \mathrm{~b}$ & $1.87 \mathrm{~b}$ & $2.44 \mathrm{ab}$ & 0.70 & 0.012 \\
\hline C18:1-n7 & $0.40 \mathrm{a}$ & $0.30 \mathrm{~b}$ & $0.29 \mathrm{~b}$ & $0.37 \mathrm{ab}$ & 0.10 & 0.007 \\
\hline C18:2-n6cis & 0.56 & 0.58 & 0.57 & 0.61 & 0.09 & 0.497 \\
\hline C18:3-n3 & 0.03 & 0.03 & 0.03 & 0.04 & 0.01 & 0.253 \\
\hline C20:0 & 0.01 & 0.01 & 0.01 & 0.02 & 0.01 & 0.226 \\
\hline C20:1-n9 & 0.05 & 0.04 & 0.03 & 0.04 & 0.02 & 0.106 \\
\hline C20:1-n7 & 0.00 & 0.00 & 0.00 & 0.01 & 0.00 & 0.080 \\
\hline C20:2-n6 & 0.02 & 0.02 & 0.02 & 0.02 & 0.01 & 0.094 \\
\hline C20:3-n6 & 0.02 & 0.02 & 0.02 & 0.02 & 0.00 & 0.208 \\
\hline C20:4-n6 & $0.12 b$ & $0.15 \mathrm{a}$ & $0.16 \mathrm{a}$ & $0.13 \mathrm{~b}$ & 0.02 & $<0.0001$ \\
\hline C20:3-n3 & 0.02 & 0.02 & 0.02 & 0.03 & 0.01 & 0.098 \\
\hline C22:4-n6 & 0.03 & 0.03 & 0.03 & 0.03 & 0.01 & 0.352 \\
\hline C22:5-n3 & 0.03 & 0.03 & 0.02 & 0.03 & 0.01 & 0.060 \\
\hline C20:5-n3 & 0.02 & 0.02 & 0.02 & 0.02 & 0.00 & 0.107 \\
\hline SFA & $2.15 \mathrm{a}$ & $1.78 \mathrm{ab}$ & $1.69 \mathrm{~b}$ & $2.09 \mathrm{ab}$ & 0.54 & 0.069 \\
\hline MUFA & $3.43 \mathrm{a}$ & $2.60 \mathrm{~b}$ & $2.44 \mathrm{~b}$ & $3.19 \mathrm{ab}$ & 0.89 & 0.010 \\
\hline PUFA-n3 & 0.13 & 0.11 & 0.11 & 0.13 & 0.03 & 0.155 \\
\hline PUFA-n6 & 0.75 & 0.80 & 0.80 & 0.81 & 0.10 & 0.306 \\
\hline PUFA & 0.86 & 0.89 & 0.89 & 0.92 & 0.12 & 0.535 \\
\hline n6/n3 & $6.02 \mathrm{~b}$ & $7.08 \mathrm{a}$ & $7.31 \mathrm{a}$ & $6.28 \mathrm{~b}$ & 0.80 & $<0.0001$ \\
\hline
\end{tabular}

*Different letters $(\mathrm{a}, \mathrm{b})$ among seasoning classes indicate significant differences $(P<0.05)$

\section{Volatile fraction development}

The aromatic profile of dry-cured hams is very complex, and is due to several factors, specifically related to the process of protein and lipid degradation during the ripening, the microbial metabolism and the traditional use of spices such as pepper and laurel during the salting. Indeed, in the present study, 97 volatile compounds were identified (Table 4) in lean ham, grouped into seven chemical families (hydrocarbons, aldehydes, ketones, esters, alcohols, acids, furans). Aldehydes consisted of 29 volatile compounds, followed by 16 esters, 14 alcohols, 13 hydrocarbons, 12 ketones, 10 acids, 2 furans and 1 nitrogenous compound. The volatile compounds' relative division in the seven families is typical of these products, as reported by Ramirez and Cava [30] on hams and by Soto et al., [31] on dry-cured loins, with aldehydes being one of the most represented groups. Aldehydes mainly originate from fatty acid autoxidation, but some of them, such as 2-methyl butanal and 3-methyl butanal, are the result of amino acid degradation, often linked to bacterial metabolism. They notably contribute to the overall aroma, thanks to their low thresholds and abundance [10, 32]. In the present work, the most abundant linear aldehydes were hexanal, nonanal and pentanal, whose main precursors were postulated to be oleic and linoleic fatty acids [33], widely present in hams. Hexanal is also considered an important indicator of lipid oxidation [34]; in fact, even if it contributes to the ham overall aroma with grassy and fresh notes, its excessive presence easily leads to unpleasant rancid notes and flavors. Regarding unsaturated aldehydes, seven were identified all over the curing (2-heptenal, 2-octenal, 2-nonenale, 2-undecenal, 2-dodecenal an 9-octadecenal), resulting from fatty acids oxidation. Eventually, polyunsaturated aldehydes consisted of six compounds, of which 


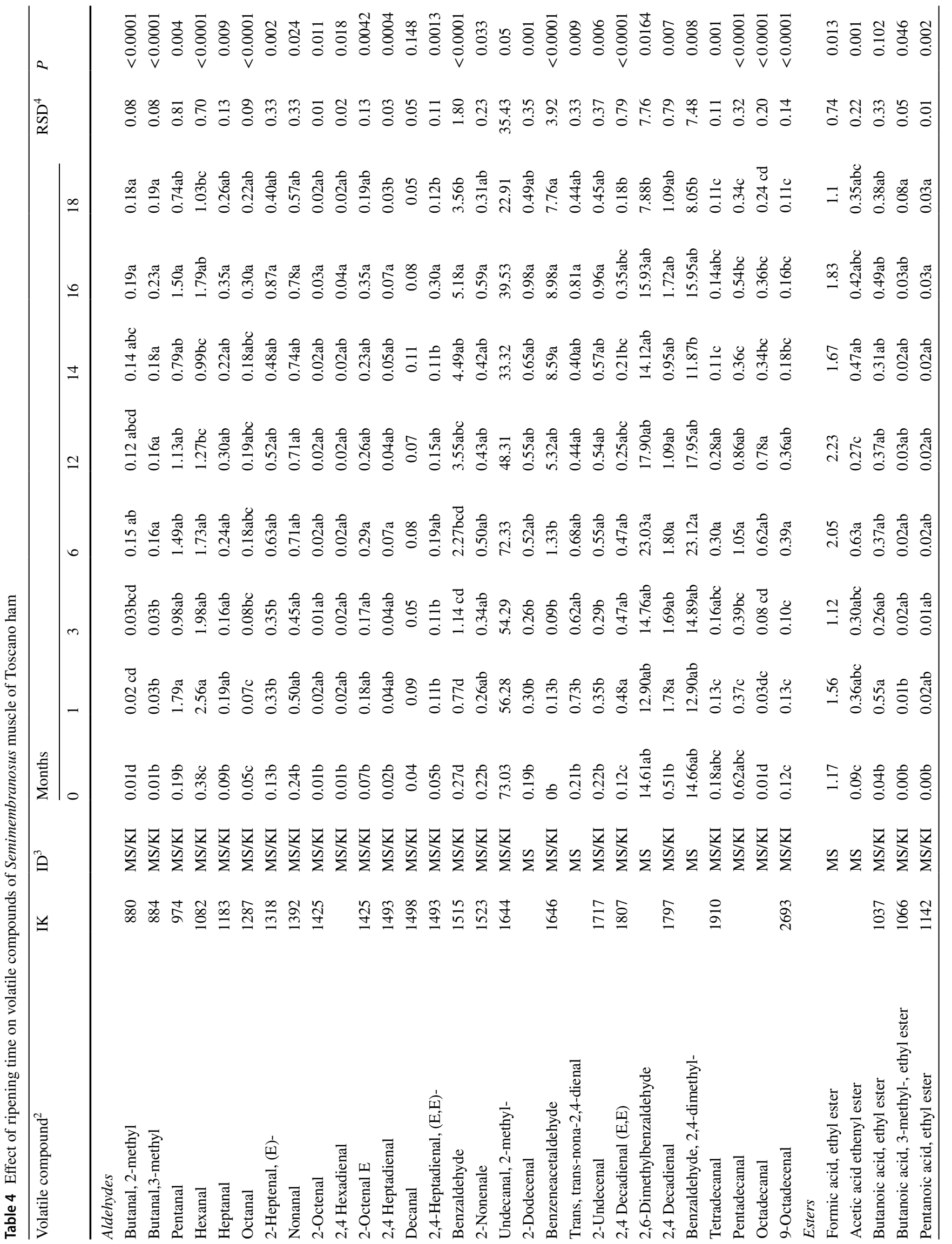




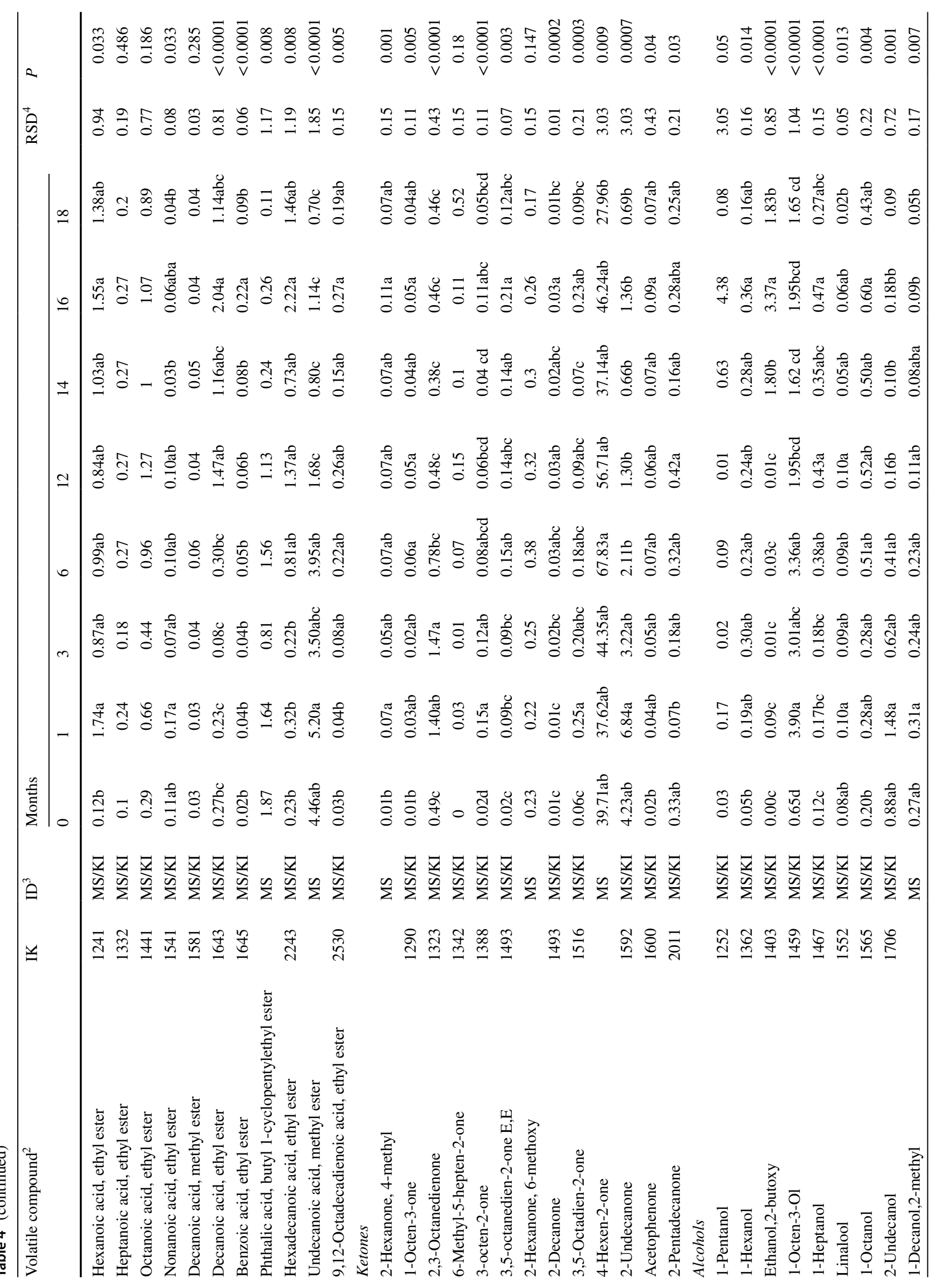




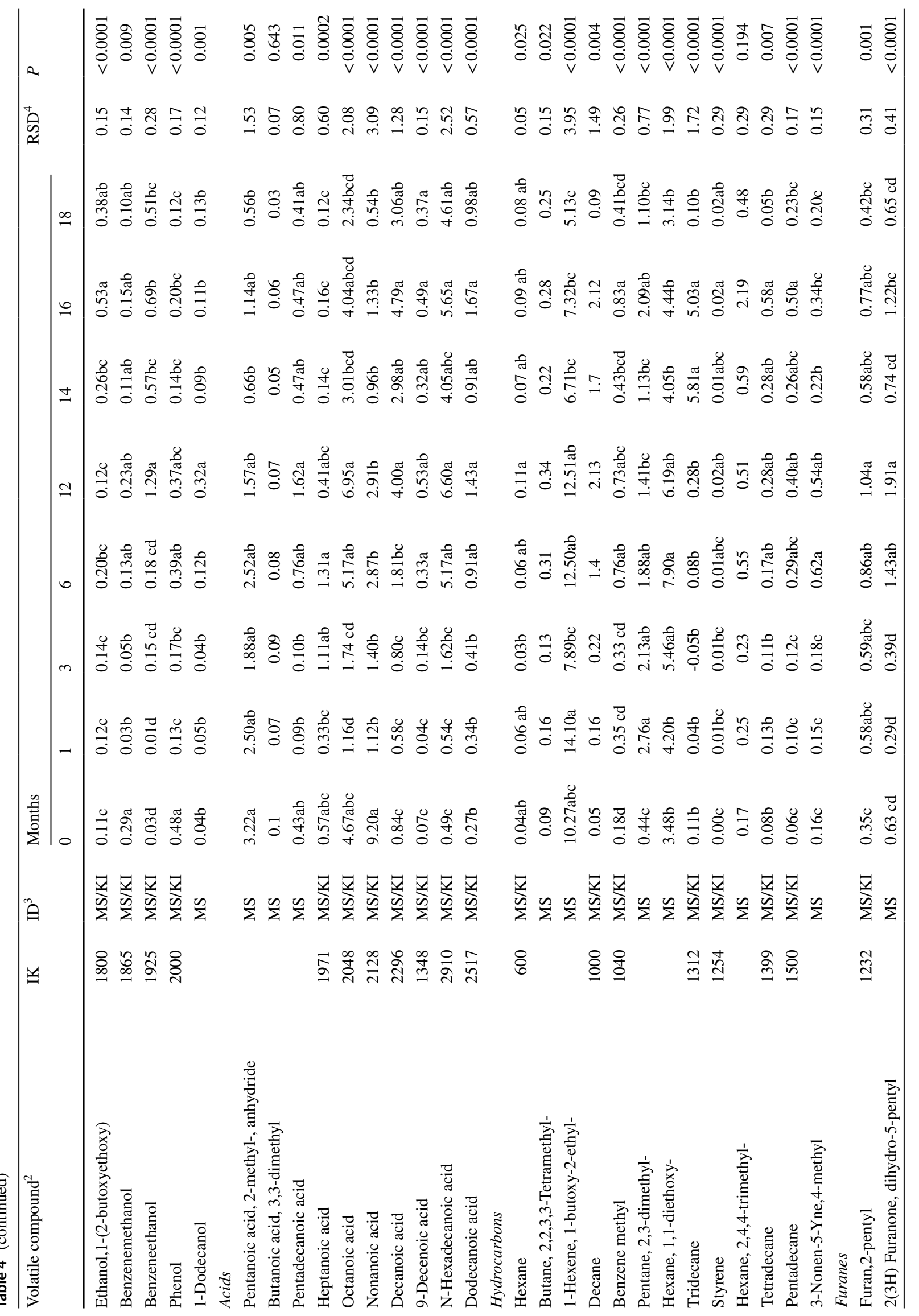


2,4-decadienal was the most abundant. Linear, unsaturated and polyunsaturated aldehydes showed almost the same trend, being characterized by a great increase in the first period, from 0 to 6 months and then decreasing from 6 to 18 months. Some exception can be observed for 2,4-hexadienal, 2,4-decadienal and 2-octenal, which remained constant especially in the last period (from 12 to 18 months). Similar results on aldehydes during the dry-curing process have also been reported for Toscano ham [8], Krški pršut [25] and Iberian ham [9], pointing out the relationship between the increasing content of aldehydes and the decreasing content of their respective fatty acid precursors.

If linear aldehydes are associated with lipid autoxidation, branched and aromatic aldehydes develop mainly from amino acid degradation. In the present work, the identified branched aldehydes are: 2-methyl butanal, 3-methyl butanal and 2-methyl-undecanal. Amino acid degradation can also lead to aromatic aldehydes, such as benzaldehyde, benzeneacetaldehyde, 2,6-dimethylbenzaldehyde and 2,4-dimethylbenzaldehyde [32]. Beyond their respective concentrations, 2-methyl butanal, 3-methyl butanal, benzaldehyde and benzeneacetaldehyde are very important due to their contribution to ham's overall aroma. 2-Methyl butanal is associated with nutty, cheesy and salty notes, while 3-methyl butanal is characterized by fruity, acorn-like, cheesy notes [35]; they both increased during all the curing process, but especially at the end (from 12 to 18 months). Benzaldehyde and benzeneacetaldehyde followed the same trend of 2-methyl butanal and 3-methyl butanal; they are characterized by unpleasant bitter and almond notes.

In addition to the aldehydes, the most abundant chemical family observed was the esters. These compounds, derived from the esterification of carboxylic acids and alcohols, were generated by lipid oxidation in the intramuscular tissues during the curing process. Esterification is usually carried out by microbial esterases [31], but, considering the low microbial counts observed inside this type of product, the microbial origin is often discarded for ham [36], preferring a chemical pathway promoted by endogenous enzymes or, at least, a concurrent formation thanks to the yeasts, moulds and bacteria found on the ham surface [37]. Esters increased during the salting and drying periods (0-6 months); then the trend became more specific for each compound but, generally, they continued to increase or remained stable during the drying period and then slightly decreased, as reported in other studies $[15,25]$. Despite their variations along the ripening, almost all the esters increased from green ham to the final product. Most of the observed esters were ethyl esters, of which the acid part was derived from the catabolism of branched amino acids (i.e., butanoic acid 3-methylethyl ester) or fatty acids (hexanoic acid, ethyl ester) [38]. The contribution of the esters to the overall aroma depends on the length of the chain: short-chained esters have fruity 
notes, while the long-chained ones have a slightly fatty odor. Moreover, the methyl branch short-chain esters seem to be positively related to the aged meat flavor [25].

Ketones can originate from different pathways, with lipid autoxidation and microbial metabolism ( $\beta$-oxidation) being the primary ones. In lean ham, a total of 13 ketones were found, of which 3 were aliphatic ketones (2-decanone, 2 -undecanone, 2-pentadecanone). These $n$-ketones were widely observed in dry-cured hams $[9,15,25,32]$ and are associated with fruity, spicy and sometimes cheesy notes [39]. Although 2-decanone and 2-pentadecanone increased until the 12th month and then decreased along the remaining seasoning period, 2-undecanone showed a different trend, increasing only until the end of the post-salting period (1 month) and then decreasing after the 6th month. 2-Undecanone was the second most abundant ketone found, but it was not strongly related to dry-cured ham, being previously found only in Kraški pršut [25] and Drniški pršut [32]. Three unsaturated ketones were also identified (1-octen-3-one, 4-hexen-2-one, 3-octen-2-one) and five polyunsaturated ones (2,3-octanedienone, 6-methyl-5-hepten-2-one, 3,5-octanedien-2-one, 6-methoxy 2-hexanone, 3,5-octadien-2-one). As aliphatic ketones, they showed a tendency to increase during the first 6 months and then decreased until the end of ripening. The only exception to this trend was observed for 6-methyl-5-hepten-2-one, which kept increasing until the 18th month. This compound, as most of methyl ketones, is the product of the $\beta$-keto decarboxylation or of saturated fatty acid $\beta$-oxidation [9]. However, Ramirez and Cava [30] reported that methyl esters may also originate from free fatty acid autooxidation, which is the most likely pathway in the presence of a small microbial population, such as inside the dry-cured ham $[1,10]$.

Fourteen alcohols were identified in green and cured hams. Linear and branched alcohols mainly result from lipid oxidation processes, while methyl branched alcohols can also be derived from the Strecker degradation of amino acids [40]. The identified alcohols are in line with those already observed on Toscano ham [15]; alcohol amount is higher in cured than in green ham, except for 2-undecanol, 2-methyl -1-decanol, 1-(2-butoxyethoxy) ethanol, benzenemethanol and phenol. Most of the observed linear alcohols likely derived from fatty acids oxidation. For example, 1-pentanol can come from linoleic acid, 1-hexanol from palmitoleic and oleic acids, while 1-octanol may be formed from oleic acid oxidation [41]. Alcohols are commonly considered minor contributors to the overall aroma because of their higher odor thresholds, mostly compared to other chemical families such as aldehydes. However, some of them, especially the straight-chain unsaturated alcohols, have lower thresholds and their contribution to ham's aroma could be significant. Indeed, in this group 1-octen-3-ol can be placed; it was found in almost all the studies on dry-cured products and easily associated with mushroom-like, earth, fatty and sometimes rancid notes [25, 38]. Moreover, 1-octen-3-ol was the most abundant alcoholic compound observed in the present study and was maintained at high levels along the curing process, as reported also by Marušić Radovčić et al. [12] and Purriños et al. [42]. In the last 6 months of ripening, the most abundant alcohols found, besides 1-octen-3-ol, were 1-pentanol (mild odor, fuel oil, fruit, balsamic odor), 2-butoxy ethanol, 1-octanol (aromatic odor, fatty, oily, walnut burnt notes) benzeneethanol, 1-hexanol and 1-heptanol (woody, green, fatty, fruity odor) [43].

Carboxylic acids mainly result from the hydrolysis of triglycerides and phospholipids, or from the oxidation of unsaturated fatty acids [37]. Organic acids are characterized by a great variability in hams of different origin. They were previously identified as important components of the volatile profile of Toscano ham [15], while in Istarski pršut, Kraški pršut, Dalmatinski pršut and Drniški pršut [32] they were present in low number. For Iberian ham, there are conflicting results: Pérez-Palacios et al. [37] as well as Carrapiso et al. [44] found only 5 acids, while Andrés et al. [45] and Martínez-Onandi et al. [46] found, respectively, 10 and 12 acids. In our study, ten acids were identified, among them octanoic, nonanoic, decanoic and hexadecanoic acids were the most abundant. They increased until the 12th month and then slightly decreased until the 18th month, following a trend which was already pointed out in Toscano ham [15]. Most of the identified acids were straight-chain aliphatic acids, and among them the short-chain ones play an important role for overall aroma, having a low perception threshold [15]. In contrast, long-chain acids, i.e., octanoic, nonanoic and decanoic acids, have higher odor thresholds and were supposed to not influence the overall aroma; they likely may act as precursors of other odor-active compounds, such as aldehydes, ketones, alcohols and shorter-chain carboxylic acids, produced through the ripening stage [38]. So, despite the abundance and the relatively large number of acids observed in our samples, they probably did not influence notably the ham overall aroma.

A total of 13 hydrocarbons were identified both in green and cured hams. Hydrocarbons can be divided into $n$-alkanes (hexane, decane, tridecane, tetradecane and pentadecane) which were produced by lipid oxidation; indeed, in our samples they all increased until the end of the drying period and then dramatically dropped from the 16th to 18th month. Some branched alkanes, one branched alkene and one branched alkine were also identified; however to the best of our knowledge, none has been previously reported in literature. This is likely due to the difficulties in identifying these types of compounds without a more specific fiber [47]. However, hydrocarbons usually have high odor thresholds and are considered not important contributors to the aroma of dry-cured products; contrariwise, aromatic 
hydrocarbons, due to their lower thresholds and potential abundance, can play an important role on overall aroma [30]. In this study, two aromatic hydrocarbons were observed, styrene and methylbenzene, both found in Iberian ham by several authors $[1,10,39,48]$. Styrene was associated with a penetrating odor and sweet smell [43], while methylbenzene presented sweet notes. This latter compound was also observed in dry-cured Chinese Jinhua ham by Huan et al. [49], who suggested that it may come from the degradation of aromatic amino acids or could also have an exogenous origin, i.e., animal feeding [37].

Eventually, the last three compounds reported were nitrogenous compounds, a furanone and a furan. Furans usually show relatively high odor thresholds, so they are considered not very important flavor contributors; however, 2-pentylfurane has a quite low odor threshold, bringing a vegetable aromatic note. Its presence could play an important role in the overall aroma, and it was considered an indicator of lipid oxidation. Indeed, this compound is a non-carboxylic oxidation product from linoleic and other omega-6 fatty acids [45]. 2-pentyl-furan showed a great increase from 0 to 12 th month, when the highest concentration was found and then it slightly decreased from the 12th to 16th month and dropped in the last 2 months of ripening. This trend is consistent with its origin connected to lipid oxidation and confirmed by results already reported for Toscano ham [15] and Iberian ham [7]. Moreover, its presence was also observed in Kraški pršut [32], Parma ham [50] and Iberian ham [36, 40].

\section{Sensory analysis}

Sensory analysis (Table 5) has outlined several differences among seasoning classes. As expected, the dehydration related to curing brought about greater hardness of 18 months hams. This emerged both by tactile assessment (tactile hardness) and chewing consistency (hardness), in accordance with the results on Teruel PDO ham [23] and Italian dry-cured ham [22]. The judges also perceived off odor and off flavor in 18-month samples. Likely, the greater length of the seasoning period might have encouraged the onset of oxidation and amino acid degradation phenomena, which resulted in off flavors not assimilable to the typical matured meat flavor. The increase of the aromatic notes classified as off flavors in relation to the length of the curing process have already been outlined in Serrano dry-cured ham [51]. However, the authors also observed how the off flavors, in limited amounts, are still important contributors to the formation of the typical cured-meat flavor of dry-cured ham. Contrariwise, Benedini et al. [22] and Cilla et al. [23], in whole slice assessment, did not find any differences between 14 and15 months and 17-18 months curing ages for any of the typical off flavors that may occur in dry-cured hams (bitter, fermented, sweet or rancid).
Table 5 Sensory attributes of Toscano ham in relation to seasoning time

\begin{tabular}{|c|c|c|c|c|c|c|}
\hline & 14 & 16 & 18 & RMSE & $P$ seasoning & $P$ panelist \\
\hline \multicolumn{7}{|l|}{ Appearance } \\
\hline Internal fat & $32.53^{1}$ & 35.76 & 33.66 & 14.59 & 0.389 & $<0.0001$ \\
\hline Color & 42.32 & 42.53 & 44.40 & 12.15 & 0.546 & $<0.0001$ \\
\hline Color uniformity & $45.69 \mathrm{a}$ & $40.53 \mathrm{~b}$ & $35.90 \mathrm{~b}$ & 16.00 & 0.002 & 0.0002 \\
\hline Marbling & 36.92 & 36.45 & 40.03 & 13.59 & 0.250 & $<0.0001$ \\
\hline Tyrosine crystals & 25.64 & 26.62 & 24.90 & 21.20 & 0.894 & 0.0136 \\
\hline \multicolumn{7}{|l|}{ Texture } \\
\hline Tactile hardness & $36.65 \mathrm{~b}$ & $37.98 \mathrm{~b}$ & $42.96 \mathrm{a}$ & 12.58 & 0.009 & $<0.0001$ \\
\hline Hardness & $27.46 \mathrm{~b}$ & $33.98 \mathrm{a}$ & $35.47 \mathrm{a}$ & 14.79 & 0.003 & $<0.0001$ \\
\hline Juiciness & 48.84 & 50.92 & 46.86 & 12.57 & 0.169 & $<0.0001$ \\
\hline \multicolumn{7}{|l|}{ Aroma } \\
\hline Odor & 48.50 & 48.87 & 44.09 & 16.12 & 0.159 & $<0.0001$ \\
\hline Off odor & $4.13 \mathrm{~b}$ & $3.89 \mathrm{~b}$ & $8.61 \mathrm{a}$ & 11.94 & 0.036 & 0.0004 \\
\hline \multicolumn{7}{|l|}{ Taste } \\
\hline Salt & 38.47 & 39.88 & 41.33 & 12.72 & 0.411 & $<0.0001$ \\
\hline Cured flavor & 50.51 & 49.37 & 45.37 & 14.55 & 0.096 & $<0.0001$ \\
\hline Off taste & $3.95 \mathrm{~b}$ & $3.80 \mathrm{~b}$ & $8.62 \mathrm{a}$ & 11.73 & 0.027 & 0.001 \\
\hline Aftertaste & 52.70 & 53.78 & 51.43 & 12.09 & 0.522 & $<0.0001$ \\
\hline General acceptability & 56.71 & 56.41 & 54.67 & 14.91 & 0.689 & $<0.0001$ \\
\hline
\end{tabular}

*Different letters $(\mathrm{a}, \mathrm{b})$ among seasoning classes indicate significant differences $(P<0.05)$

${ }^{1}$ Data are expressed in $\mathrm{mm}$, as reported by each panelist on a $10-\mathrm{cm}$ unstructured scale whose extremes were "very low" and "very high" 


\section{Discriminant analysis}

The stepwise discriminant analysis (SDA) applied in the first scenario selected 26 compounds able to discriminate low maturing class (LMC) from high maturing class (HMC) (Table 6).

Having only two groups (LMC and HMC) the CDA, developed by using the 26 selected compounds produced one CAN, whose canonical coefficients (CCs) are listed in Table 6. The graph of the CAN (Fig. 1) showed a clean separation between the two groups and the Hotelling's test was highly significant ( $p$ value $<0.0001$ ). Among the 26 compounds, those with a $\mathrm{CC}$ greater than 1 in absolute value played an important role in discriminating the two curing classes. Moreover, observing Fig. 1, volatile compounds listed in Table 6 with positive CCs can be considered more related to HMC, whereas those whose CCs are negative can be ascribed to LMC. The most influencing compounds

Table 6 Volatile compounds of Semimembranosus muscle of Toscano ham selected by Stepwise discriminant analysis (SDA) and their relative canonical discriminant analysis (CDA) scores (Can1) used to separate low maturing classes (LMC) and high maturing classes (HMC)

\begin{tabular}{lll}
\hline Volatile compounds & Chemical family & Can1 \\
\hline Pentane, 2,3-dimethyl- & Hydrocarbon & $-1,69$ \\
Acetophenone & Keton & $-1,54$ \\
9-Decenoic acid & Acid & $-1,31$ \\
Undecanoic acid, methylester & Ester & $-0,85$ \\
2,4 Heptadienal & Aldehyde & $-0,41$ \\
Tridecane & Hydrocarbon & $-0,36$ \\
Butanal, 2-methyl & Aldehyde & $-0,36$ \\
Decanal & Aldehyde & $-0,28$ \\
Octadecanal & Aldehyde & $-0,28$ \\
1,5-Diphenyl-3-methylthio-1,2,4- & Nitrogenous compound & $-0,26$ \\
triazole & & \\
Nonanoic acid, ethylester & Ester & $-0,13$ \\
Benzeneethanol & Alcohol & $-0,08$ \\
3,5-Octadien-2-one & Keton & $-0,02$ \\
Pentanal & Aldehyde & $-0,01$ \\
Tetradecanal & Aldehyde & 0,08 \\
4-Hexen-2-one & Keton & 0,16 \\
Decanoic acid, ethylester & Ester & 0,29 \\
6-Methyl-5-hepten-2-one & Keton & 0,36 \\
Benzenemethyl & Hydrocarbon & 0,37 \\
Ethanol,2-butoxy & Alcohol & 0,49 \\
Styrene & Hydrocarbon & 0,52 \\
Heptanal & Aldehyde & 0,72 \\
Pentanoic acid, ethylester & Ester & 1,33 \\
3-Octen-2-one & Keton & 1,34 \\
Benzeneacetaldehyde & Aldehyde & 1,48 \\
Dodecanoic acid & Acid & 4,20 \\
\hline & & \\
& &
\end{tabular}

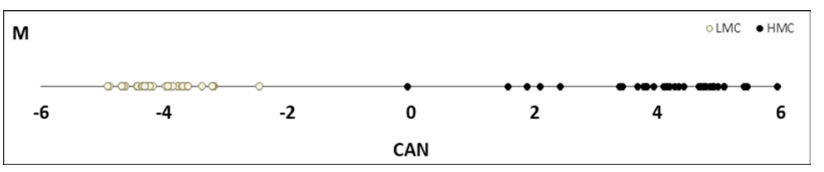

Fig. 1 Separation of the 26 compounds selected by SDA relatively to their capability in correctly differentiating samples between low maturing classes (LMC) and high maturing classes (HMC). $170 \times 32 \mathrm{~mm}(120 \times 120 \mathrm{DPI})$

pointed out by multivariate analysis were pentane, 2,3-dimethyl, acetophenone and 9-decenoic acid for LMC and dodecanoic, benzeneacetaldehyde, 3-octen-2-one and pentanoic acid ethylester for HMC. Dodecanoic acid, having the highest absolute value in CAN1 $(\mathrm{CC}=4.20)$, is the most effective compound identifying HMC hams; indeed, its evolution during curing was characterized by a very clear ascending trend from 0 to 18 th month, so it was strongly present in HMC samples and less represented in LMC ones. Regardless of being a good discriminant in a chemical analysis, it had a very high perception threshold (Burdock), so it did not contribute to overall aroma and, likely, it was not effective in a sensorial assessment perspective. The other highdiscriminant compounds (in absolute value terms) followed the same trend of dodecanoic acid during ripening, except for 3-octen-2one, whose lower occurrence in HMC than in LMC seemed to act as the discriminant factor. Finally, DA developed by using the selected compounds was correctly assigned to all but one of the samples.

In the second scenario, the SDA was applied only to HMC hams (divided in 12, 14, 16 and 18 months of seasoning). The 17 selected compounds are listed in Table 7. The distances between samples seasoned for 12 months and the others were, on average, twice as high as the reciprocal distances among 14, 16 and 18 months (Table 8). In this case, Hotelling's $t$ test was highly significant. Samples seasoned for 14 and 16 months were not significantly differentiated ( $p$ value $=0.05$ ) and samples seasoned for 14 and 18 months had a $p$ value equal to 0.02 . Having four groups, the CDA derived three CANs. However, the first two CANs accounted for $93 \%$ of the total variance and were able to highlight differences among groups. CCs for CAN1 and CAN2 are reported in Table 7. Figure 2 displays graphs both for scores (a) and for loadings (b). In particular, (Fig. 2a) CAN1 separated the "12 months" seasoning class from the other classes. Stepwise and canonical techniques are not largely applied in this field, contrary to the widespread PCA techniques. However, as far as results can be compared, also Jurado et al. [7] reported a clear separation between 12-month Iberian hams and the older ones.

However, once submitted to DA, they were not able to completely discriminate the four groups. Observing Fig. 2 b, the main VOCs associated with the " 12 months" 
Table 7 Volatile compounds selected by stepwise discriminant analysis (SDA) and their relative canonical discriminant analysis (CDA) scores (Can1, Can2) used to classify samples in their respective seasoning times $(12$, $14,16,18)$, within the high maturing class (HMC)

\begin{tabular}{llll}
\hline Volatile compounds & Chemical family & Can1 & Can2 \\
\hline 1,5-Diphenyl-3-methylthio-1,2,4-triazole & Nitrogenous compound & -2.2 & 4.93 \\
Tridecane & Hydrocarbon & 1.2 & 1.75 \\
1-Hexanol & Alcohol & 1.05 & 0.22 \\
Nonanal & Aldehyde & -1.7 & 0.68 \\
Ethanol,2-butoxy & Alcohol & 2.9 & -2.22 \\
2-Hexanone, 6-methoxy & Keton & -1.47 & 1.04 \\
Decanal & Aldehyde & -0.17 & -0.41 \\
1-Hexene, 1-butoxy-2-ethyl & Hydrocarbon & -0.21 & 0.11 \\
Benzoic acid, ethyl ester & Ester & 0.3 & 0.1 \\
3-Nonen-5-Yne,4-methyl & Hydrocarbon & 1.25 & -3.62 \\
Pentadecanoic acid & Acid & -0.68 & 0.62 \\
Pentanal & Aldehyde & -0.34 & -0.95 \\
Heptanoic acid & Acid & -0.9 & 0.39 \\
Phenol & Alcohol & 1.59 & -1.84 \\
2(3H) Furanone, dihydro-5-pentyl & Furan & -0.51 & 0.03 \\
Nonanoic acid & Acid & 0.39 & -0.02 \\
Undecanoic acid, methyl ester & Ester & -0.56 & 1.47 \\
Proportion of explained variation & & 0,67 & 0,26 \\
\hline
\end{tabular}

Table 8 Mahalanobis distances between group centroids of HMC samples and, in brackets, the corresponding Hotelling's test of significance

\begin{tabular}{llll}
\hline $\begin{array}{l}\text { Months of } \\
\text { seasoning }\end{array}$ & 14 & 16 & 18 \\
\hline 12 & $8.7(<0.001)$ & $12.9(<0.001)$ & $10.0(<0.001)$ \\
14 & & $2.5(0.05)$ & $3.2(0.02)$ \\
16 & & & $5.8(<0.001)$ \\
\hline
\end{tabular}

class were nonanal, 1,5-diphenyl-3-methylthio-1,2,4triazole and 6-methoxy 2-hexanone. CAN2 was able to differentiate "18 months" seasoning class from the others, especially from the " 16 months" seasoning class (Fig. 2a). In this case, the compounds that most affected the class separation are the same as those in CAN1, but with reversed signs. However, 3-nonen-5-yne,4-methyl plays an important role in CAN2 and probably also in the characterization of 18 months samples with respect to the 14 and 16 ones.

These results suggested that the 26 compounds identified in the first scenario (Table 6) could be a useful tool to quickly determine the curing age of unknown samples. This could lead to interesting commercial applications, considering that Toscano ham is commercialized starting from the 12th month of seasoning. Indeed, before the 12th month, the product has not developed yet the set of physical, chemical and organoleptic characteristics traditionally associated with this type of dry-cured ham. Despite the loss of accuracy observed in the second scenario, also the 17 compounds (Table 7) identified as discriminating within the HMC samples turned out to be an interesting way to separate at least 12th months samples from the 18th months ones.

\section{Conclusions}

Results on physical, chemical and sensory analysis agree in outlining a decrease in moisture along the curing process. Moreover, a decrease in total lipids, SFA and MUFA amounts were observed between green and 14and 16-months hams, which is in accordance with VOCs evolution along curing. The use of GC-MS technique allowed following the aroma development in the Toscano ham along the entire manufacturing process, from fresh until the 18th month of seasoning, when ham is considered a high-quality product. The volatile profile allowed to correctly identify fresh or seasoned hams and, despite a loss of accuracy once moved into the HMC class, this type of data processing demonstrated to be able to allocate most of the hams to their respective maturing classes. Thanks to the specific aroma developing pattern, the volatile compounds analysis along with an appropriate data handling could be an interesting tool to check the curing stage of hams, also in the perspective of fraud prevention. 
a

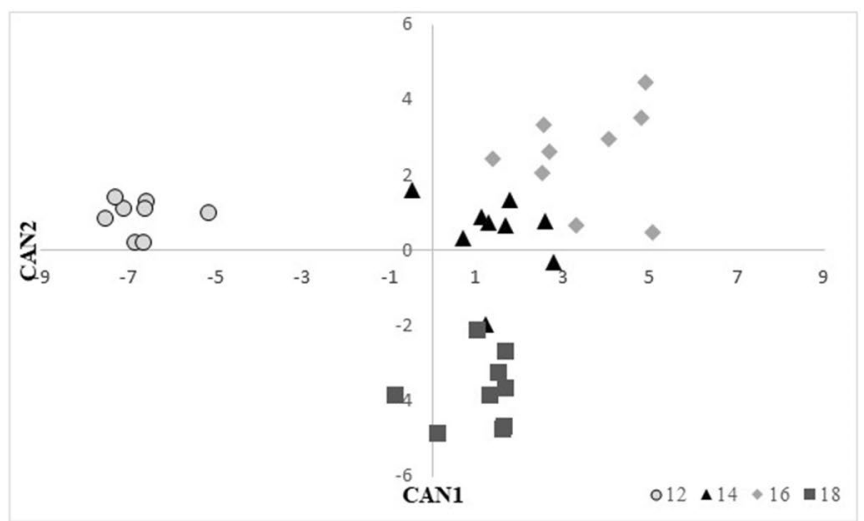

b

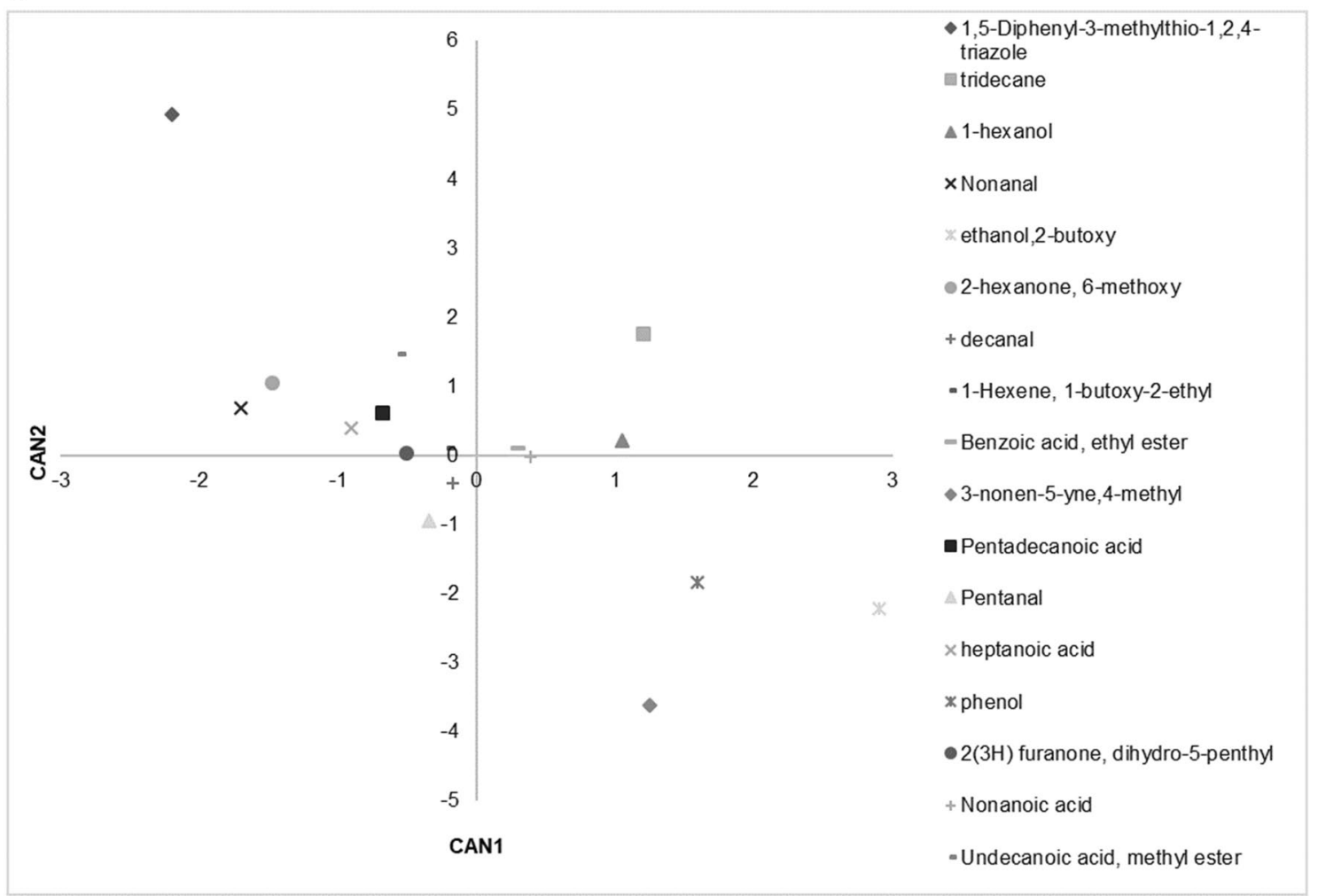

Fig. 2 a Scores of Canonical discriminant analysis within HMC samples: $12,14,16,18$ months of seasoning. $127 \times 76 \mathrm{~mm}(120 \times 120$ DPI) b Loadings of canonical discriminant analysis within HMC samples: volatile compounds identified by stepwise discriminant analysis. 175 x $119 \mathrm{~mm}(150 \times 150 \mathrm{DPI})$
Acknowledgements The project was supported by Regione Toscana and Consorzio del Prosciutto Toscano. The authors would like to thank Mr. Aldo Neri and the staff of Valdinievole salumi srl.

\section{Compliance with ethical standards}

Conflict of interest The authors declare that they have no conflict of interest.

Compliance with ethics requirements This article does not contain any studies with human or animal subjects. 
Open Access This article is distributed under the terms of the Creative Commons Attribution 4.0 International License (http://creativeco mmons.org/licenses/by/4.0/), which permits unrestricted use, distribution, and reproduction in any medium, provided you give appropriate credit to the original author(s) and the source, provide a link to the Creative Commons license, and indicate if changes were made.

\section{References}

1. Sabio E, Vidal-Aragón MC, Bernalte MJ, Gata JL (1998) Volatile compounds present in six types of dry-cured ham from south European countries. Food Chem 61:493-503. https://doi. org/10.1016/S0308-8146(97)00079-4

2. Laureati M, Buratti S, Giovanelli G et al (2014) Characterization and differentiation of Italian Parma, San Daniele and Toscano drycured hams: a multi-disciplinary approach. Meat Sci 96:288-294. https://doi.org/10.1016/j.meatsci.2013.07.014

3. Bermúdez R, Franco D, Carballo J, Lorenzo JM (2015) Influence of type of muscle on volatile compounds throughout the manufacture of Celta dry-cured ham. Food Sci Technol Int 21:581-592. https://doi.org/10.1177/1082013214554935

4. Pérez-Santaescolástica C, Carballo J, Fulladosa E et al (2018) Effect of proteolysis index level on instrumental adhesiveness, free amino acids content and volatile compounds profile of drycured ham. Food Res Int 107:559-566. https://doi.org/10.1016/j. foodres.2018.03.001

5. Timón ML, Ventanas J, Carrapiso AI et al (2001) Subcutaneous and intermuscular fat characterisation of dry-cured Iberian hams. Meat Sci 58:85-91. https://doi.org/10.1016/S0309 -1740(00)00136-4

6. Ruiz J, Ventanas J, Cava R et al (1999) Volatile compounds of drycured Iberian ham as affected by the length of the curing process. Meat Sci 52:19-27. https://doi.org/10.1016/s0309-1740(98)00144 $-2$

7. Jurado Á, Carrapiso AI, Ventanasa J, García C (2009) Changes in SPME-extracted volatile compounds from Iberian ham during ripening. Grasas Aceites 60:262-270. https://doi.org/10.3989/ gya. 131008

8. Pugliese C, Sirtori F, Calamai L, Franci O (2010) The evolution of volatile compounds profile of "Toscano" dry-cured ham during ripening as revealed by SPME-GC-MS approach. J Mass Spectrom 45:1056-1064. https://doi.org/10.1002/jms.1805

9. Narváez-Rivas M, Gallardo E, León-Camacho M (2014) Chemical changes in volatile aldehydes and ketones from subcutaneous fat during ripening of Iberian dry-cured ham. Prediction of the curing time. Food Res Int 55:381-390. https://doi.org/10.1016/j. foodres.2013.11.029

10. Sánchez-Peña CM, Luna G, García-González DL, Aparicio R (2005) Characterization of French and Spanish dry-cured hams: influence of the volatiles from the muscles and the subcutaneous fat quantified by SPME-GC. Meat Sci 69:635-645. https://doi. org/10.1016/j.meatsci.2004.10.015

11. Gaspardo B, Procida G, Toso B, Stefanon B (2008) Determination of volatile compounds in San Daniele ham using headspace GC-MS. Meat Sci 80:204-209. https://doi.org/10.1016/j.meats ci.2007.11.021

12. Marušić Radovčić N, Vidaček S, Janči T, Medić H (2016) Characterization of volatile compounds, physico-chemical and sensory characteristics of smoked dry-cured ham. J Food Sci Technol 53:4093-4105. https://doi.org/10.1007/s13197-016-2418-2

13. AOAC (2012) Official methods of analysis of AOAC international, 19th ed. AOAC 53 International, Gaithersburg, Maryland, USA

14. Sirtori F, Crovetti A, Acciaioli A et al (2015) Effect of replacing a soy diet with Vicia faba and Pisum sativum on performance, meat and fat traits of Cinta Senese pigs. Ital J Anim Sci 14:99-104. https://doi.org/10.4081/ijas.2015.3659

15. Pugliese BC, Sirtori F, Ruiz J et al (2009) Effect of pasture on chestnut or acorn on fatty acid composition and aromatic profile of fat of Cinta Senese dry-cured ham. Grasas Aceites 60:271-276. https://doi.org/10.3989/gya.130208

16. SAS Institute Inc (2011) SAS/STAT® 9.3 User's Guide. SAS Institute Inc, Cary, $\mathrm{NC}$

17. De Maesschalck R, Jouan-Rimbaud D, Massart DLL (2000) The Mahalanobis distance. Chemom Intell Lab Syst 50:1-18. https:// doi.org/10.1016/S0169-7439(99)00047-7

18. Dimauro C, Cellesi M, Pintus MA, MacCiotta NPP (2011) The impact of the rank of marker variance-covariance matrix in principal component evaluation for genomic selection applications. J Anim Breed Genet 128:440-445. https://doi.org/10.111 1/j.1439-0388.2011.00957.x

19. Bermúdez R, Franco D, Carballo J, Lorenzo JM (2014) Physicochemical changes during manufacture and final sensory characteristics of dry-cured Celta ham. Effect of muscle type. Food Contr 43:263-269. https://doi.org/10.1016/j.foodcont.2014.03.028

20. García-García AB, Fernández-Valle ME, Castejón D et al (2019) Use of MRI as a predictive tool for physicochemical and rheologycal features during cured ham manufacturing. Meat Sci 48:171-180. https://doi.org/10.1016/j.meatsci.2018.10.015

21. Giovanelli G, Buratti S, Laureati M, Pagliarini E (2016) Evolution of physicochemical, morphological and aromatic characteristics of Italian PDO dry-cured hams during processing. Eur Food Res Technol 242:1117-1127. https://doi.org/10.1007/s0021 7-015-2616-6

22. Benedini R, Parolari G, Toscani T, Virgili R (2012) Sensory and texture properties of Italian typical dry-cured hams as related to maturation time and salt content. Meat Sci 90:431-437. https:// doi.org/10.1016/j.meatsci.2011.09.001

23. Cilla I, Martínez L, Beltrán JA, Roncalés P (2005) Factors affecting acceptability of dry-cured ham throughout extended maturation under "bodega" conditions. Meat Sci 69(4):789-795. https:// doi.org/10.1016/j.meatsci.2004.11.012

24. Cava R, Estévez M, Morcuende D, Antequera T (2003) Evolution of fatty acids from intramuscular lipid fractions during ripening of Iberian hams as affected by $\alpha$-tocopheryl acetate supplementation in diet. Food Chem 81(2):199-207. https://doi.org/10.1016/S0308 $-8146(02) 00413-2$

25. Pugliese C, Sirtori F, Škrlep M et al (2015) The effect of ripening time on the chemical, textural, volatile and sensorial traits of Bicep femoris and Semimembranosus muscles of the Slovenian dry-cured ham Kraški pršut. Meat Sci 100:58-68. https://doi. org/10.1016/j.meatsci.2014.09.012

26. Delgado GL, Gómez CS, Rubio LMS et al (2002) Fatty acid and triglyceride profiles of intramuscular and subcutaneous fat from fresh and dry-cured hams from hairless mexican pigs. Meat Sci 61(1):61-65. https://doi.org/10.1016/S0309-1740(01)00163-2

27. Larrea V, Pérez-Munuera I, Hernando I et al (2007) Chemical and structural changes in lipids during the ripening of Teruel drycured ham. Food Chem 102:494-503. https://doi.org/10.1016/j. foodchem.2006.03.035

28. Martín L, Córdoba JJ, Ventanas J, Antequera T (1999) Changes in intramuscular lipids during ripening of Iberian dry-cured ham. Meat Sci 51:129-134. https://doi.org/10.1016/S0309 $-1740(98), 00109-0$

29. Coutron-gambotti C, Gandemer G (1999) Lipolysis and oxidation in subcutaneous adipose tissue during dry-cured ham processing. Food Chem 64:95-101

30. Ramírez MR, Cava R (2007) Effect of Iberian $\times$ Duroc genotype on dry-cured loin quality. Meat Sci 76:333-341. https://doi. org/10.1016/j.meatsci.2006.11.017 
31. Soto E, Hoz L, Ordóñez JA et al (2008) Impact of feeding and rearing systems of Iberian pigs on volatile profile and sensory characteristics of dry-cured loin. Meat Sci 79:666-676. https:// doi.org/10.1016/j.meatsci.2007.10.031

32. Petričević S, Marušić Radovčić N, Lukić K et al (2018) Differentiation of dry-cured hams from different processing methods by means of volatile compounds, physico-chemical and sensory analysis. Meat Sci 137:217-227. https://doi.org/10.1016/j.meats ci.2017.12.001

33. Wang D, Sun J, Huang G et al (2009) Carbohydrates. In: Belitz H-D, Grosch W, Schieberle P (eds) Food Chemistry, 4th edn. Springer, Berlin, pp 35-106

34. Brunton NP, Cronin DA, Monahan FJ, Durcan R (2000) A comparison of solid-phase microextraction (SPME) fibres for measurement of hexanal and pentanal in cooked turkey. Food Chem 68:339-345. https://doi.org/10.1016/S0308-8146(99)00203-4

35. Burdock GA (2010) Fenaroli's handbook of flavor ingredients, 6th ed. CRC Press

36. Flores M, Grimm CC, Toldrá F, Spanier AM (1997) Correlations of sensory and volatile compounds of Spanish "Serrano" drycured ham as a function of two processing times. J Agric Food Chem 45:2178-2186. https://doi.org/10.1021/jf960862c

37. Pérez-Palacios T, Ruiz J, Martín D et al (2010) Influence of precure freezing on the profile of volatile compounds during the processing of Iberian hams. J Sci Food Agric 90:882-890. https://doi. org/10.1002/jsfa.3899

38. Therron L, Tournayre P, Kondjoyan N et al (2010) Analysis of the volatile profile and identification of odour-active compounds in Bayonne ham. Meat Sci 85:453-460. https://doi.org/10.1016/j. meatsci.2010.02.015

39. García-González DL, Tena N, Aparicio-Ruiz R, Morales MT (2008) Relationship between sensory attributes and volatile compounds qualifying dry-cured hams. Meat Sci 80:315-325. https ://doi.org/10.1016/j.meatsci.2007.12.015

40. García-González DL, Aparicio R, Aparicio-Ruiz R (2013) Volatile and amino acid profiling of dry cured hams from different swine breeds and processing methods. Molecules 18:3927-3947. https://doi.org/10.3390/molecules 18043927

41. Flores J (1997) Mediterranean vs northern European meat products. Processing technologies and main differences. Food Chem 59:505-510. https://doi.org/10.1016/S0308-8146(97)00011-3
42. Purriños L, García Fontán MC, Carballo J, Lorenzo JM (2013) Study of the counts, species and characteristics of the yeast population during the manufacture of dry-cured "lacón" Effect of salt level. Food Microbiol 34:12-18. https://doi.org/10.1016/j. fm.2012.11.003

43. Calkins CR, Hodgen JM (2007) A fresh look at meat flavor. Meat Sci 77:63-80. https://doi.org/10.1016/j.meatsci.2007.04.016

44. Carrapiso AI, Noseda B, García C et al (2015) SIFT-MS analysis of Iberian hams from pigs reared under different conditions. Meat Sci 104:8-13. https://doi.org/10.1016/j.meatsci.2015.01.012

45. Andrés AI, Cava R, Ruiz J (2002) Monitoring volatile compounds during dry-cured ham ripening by solid-phase microextraction coupled to a new direct-extraction device. J Chromatogr A 963:83-88. https://doi.org/10.1016/S0021-9673(02)00139-5

46. Martínez-Onandi N, Rivas-Cañedo A, Ávila M et al (2017) Influence of physicochemical characteristics and high pressure processing on the volatile fraction of Iberian dry-cured ham. Meat Sci 131:40-47. https://doi.org/10.1016/j.meatsci.2017.04.233

47. Petrón MJ, Tejeda JF, Muriel E et al (2005) Study of the branched hydrocarbon fraction of intramuscular lipids from Iberian drycured ham. Meat Sci 69:129-134. https://doi.org/10.1016/j.meats ci.2004.06.014

48. Narváez-Rivas M, Vicario IM, Alcalde MJ, León-Camacho M (2010) Volatile hydrocarbon profile of Iberian dry-cured hams. A possible tool for authentication of hams according to the fattening diet. Talanta 81:1224-1228. https://doi.org/10.1016/j.talan ta.2010.02.013

49. Huan Y, Zhou G, Zhao G et al (2005) Changes in flavor compounds of dry-cured Chinese Jinhua ham during processing. Meat Sci 71:291-299. https://doi.org/10.1016/j.meatsci.2005.03.025

50. Barbieri G, Bolzoni L, Parolari G et al (1992) Flavor compounds of dry-cured ham. J Agric Food Chem 40:2389-2394. https://doi. org/10.1021/jf00024a013

51. Flores M, Ingram DA, Betti KL et al (1997) Sensory characteristics of spanish "serrano" dry-cured ham. J Sens Stud 12:169-179

Publisher's Note Springer Nature remains neutral with regard to jurisdictional claims in published maps and institutional affiliations. 